\title{
ЭФФЕКТИВЕН ЛИ ЛИБЕРАЛИЗМ? (СОВРЕМЕННЫЙ ЛИБЕРАЛИЗМ КАК МИКС НЕСОЕДИНИМЫХ ХАРАКТЕРИСТИК)
}

\author{
(c) 2021 Гуськова Марина Федоровна \\ доктор экономических наук, профессор, профессор кафедры «Менеджмент качества» \\ ФГБОУ ВО РУТ (МИИТ), Россия, Москва
}

(C) 2021 Иванова Валентина Николаевна

доктор экономических наук, профессор, лауреат премии Правительства Российской Федерации в области образования, заведующая кафедрой, президент

ФГБОУ ВО МГУТУ (ПКУ), Россия, Москва

(c) 2021 Стерликов Павел Федорович

доктор экономических наук, профессор, декан экономического факультета

ФГБОУ ВО МГМСУ, Россия, Москва

(c) 2021 Стерликов Федор Федорович

доктор экономических наук, профессор, лауреат премии Правительства Российской Федерации в области науки и техники

ФГБОУ ВО МГУТУ (ПКУ), Россия, Москва

Проведен краткий анализ взглядов основных разновидностей либерализма на категорию «справедливость»: экономическую, социальную и культурную. Особое внимание уделялось оценке возможности реализации основных конституирующих характеристик либерализма в современных экономических условиях. Отмечена недостаточность исследований только на уровне видимости формы экономических отношений и необходимость проведения исследований на сущностном теоретическом уровне.

Ключевые слова: либерализм, справедливость экономическая, социальная, культурная; экономическая форма и экономическая сущность.

\section{1. Разновидности либерализма}

Классический либерализм содержит несколько разновидностей - экономический, культурный и социальный.

ЭКОНОМИЧЕСКИЙ ЛИБЕРАЛИЗМ ОсНОВЫвается на доктрине laissez-faire, допускающей минимальное государственное вмешательство в экономику. Идеологи экономического либерализма пропагандируют свободный рынок, поддерживают максимальную свободу торговли и конкуренции. Они заверяют, что политическая свобода (политическая справедливость) и социальная справедливость неотделимы от экономической свободы.

Среди множества определений термина «экономическая свобода» чаще всего используется понятие экономической свободы, базирующееся на концепции свободного рынка и частной собственности или, другими словами, ТОЛЬКО НА РЫНОЧНОЙ ЭКОНОМИКЕ.

Для определенной общественно-экономической формации, для определенного единства экономики и политики, имеется строго определенное содержание политической справедливости. Например, в феодальном обществе это сословная политическая справедливость. И если одними членами общества она считалась естественной справедливостью, то другими несправедливостью. И, естественно, в капиталистическом обществе, рыночном единстве экономики и политики социальная справедливость выражается еще большим разрывом оценок справедливости и несправедливости, большей дифференциацией справедливости и несправедливости.

Итак, экономическая свобода не гарантирует ни политической, ни социальной справедливости для различных способов производства.

Конкуренция в рыночной экономике стимулирует предпринимателя, по мере возможности, производить полезные обществу блага, если его производство осуществляется в рамках общественных потребностей. Эта часть предпринимательской деятельности способствует прогрес- 
су экономике и не препятствует обогащению удачливого предпринимателя. В тоже время рыночная экономика поощряет социальную несправедливость общества.

КУЛЬТУРНЫЙ ЛИБЕРАЛИЗМ - течение либерализма, ведущим принципом которого является невмешательство государства в личную жизнь. Культурный либерализм допускает соблюдение собственных культурных норм и провозглашает мультикультурализм.

Культурный либерализм выступает против государственного контроля азартных игр, проституции, против государственного регулирования: условий вступления в половые отношения, проведения абортов. Это течение либерализма не одобряют ограничения в использовании противозачаточных средств, запрет эвтаназии, употребления алкоголя и других наркотиков.

Апологеты культурного либерализма считают, что и общество не должно регулировать кодекс поведения и правила (семья, брак)..

Немалую роль мультикультурализм играет во внутренней политике Германии, Нидерландов, Франции, Швеции и других европейских государств.

СОЦИАЛЬНЫЙ ЛИБЕРАЛИЗМ допускает вмешательство государства в экономические процессы.

Апологеты социального либерализма утверждают - реализовать главный принцип либерализма о праве индивида на самоопределение и самореализацию - не может быть обеспечен только собственными усилиями индивида.

Создание равных стартовых возможностей невозможно без вмешательства государства. Выравнивание стартовых условий снимает напряженность в общественных отношениях и стимулирует социальную и политическую стабильности. Перераспределяя общественный продукт государство, по мнению либералов, поддерживает социально слабых членов общества. Социальные либералы являются апологетами капиталистического типа экономики, поддерживают социально-ориентированный тип рыночной экономики.

Необходимость государственного вмешательства в экономические процессы, по мнению социальных либералов, обусловлена целью ослабления засилья монополий, поддержания конкурентной рыночной среды. Общество должно обеспечить экономическую справедливость - обеспечить доход членов общества в соответствии с их вкладом в общее благо. Для этого оно изымает часть дохода богатых через налоги и перераспределяет её в интересах беднейших слоев общества. В результате такого перераспределения достигается не только улучшение условий жизни бедных членов общества, но и увеличивается рыночный спрос, растет внутренний рынок, что обеспечит рост всей экономики в стране.

Предложенные социальными либералами действия государства смягчают конфликты в обществе и создают условия превращения «капитализма эпохи свободной конкуренции» в социальный капитализм. Другими словами, в обществе создается так называемая «социальная экономика». Экономика базируется на частной собственности, рыночные отношения регулируются государством.

Проведенный анализ показал, что все разновидности либерализма: экономический, культурный и социальный предполагают существование общества непременно в рыночной экономике (Таблица 1). Однако рыночная экономика не обеспечивает экономическую справедливость.

Таблица 1. Сравнение основных характеристик экономического, культурного и социального либерализма

\begin{tabular}{|c|c|c|c|c|}
\hline $\begin{array}{c}\text { Составляю- } \\
\text { щиелиберализма }\end{array}$ & $\begin{array}{c}\text { Основные характе- } \\
\text { ристики }\end{array}$ & $\begin{array}{c}\text { Показатель эконо- } \\
\text { мической справед- } \\
\text { ливости }\end{array}$ & $\begin{array}{c}\text { Показатель полити- } \\
\text { ческой справедли- } \\
\text { вости }\end{array}$ & Общие выводы \\
\hline 1. Экономический & $\begin{array}{l}\text { Рынок, свобода } \\
\text { торговли и конку- } \\
\text { ренции }\end{array}$ & $\begin{array}{l}\text { Поощряет экономи- } \\
\text { ческую несправед- } \\
\text { ливость общества }\end{array}$ & $\begin{array}{l}\text { Провозглашает } \\
\text { политическую спра- } \\
\text { ведливость }\end{array}$ & $\begin{array}{l}\text { Только для рыноч- } \\
\text { ной экономики }\end{array}$ \\
\hline 2. Культурный & $\begin{array}{l}\text { Государство и обще- } \\
\text { ство не навязывают } \\
\text { ко-декса поведения }\end{array}$ & $\begin{array}{l}\text { Допускает экономи- } \\
\text { ческую несправед- } \\
\text { ливость общества }\end{array}$ & $\begin{array}{l}\text { Провозглашает } \\
\text { мультикультура- } \\
\text { лизм }\end{array}$ & $\begin{array}{l}\text { Поощряет рыноч- } \\
\text { ный индивидуализм }\end{array}$ \\
\hline 3. Социальный & $\begin{array}{l}\text { Вмешательство } \\
\text { государства в эконо- } \\
\text { мические процессы. }\end{array}$ & $\begin{array}{l}\text { Равенство возмож- } \\
\text { ностей обеспечива- } \\
\text { ет государство }\end{array}$ & $\begin{array}{l}\text { Право индивида на } \\
\text { самоопре-деление и } \\
\text { самореализацию }\end{array}$ & $\begin{array}{l}\text { Социально- } \\
\text { ориентированная } \\
\text { рыночная эконо-- } \\
\text { мика }\end{array}$ \\
\hline
\end{tabular}




\section{2. Социальная справедливость}

По признаку различия функций справедливости чаще всего исследователями предлагается различать следующие виды справедливости:

- компенсирующая - обеспечение заработанного вознаграждения за выполнение полезных обществу продуктов и работ;

- стимулирующая этические действия, мотивируя дальнейшие общественно-полезные действия;

- благотворительная - добровольный отказ от заработанного вознаграждения по велению совести в пользу улучшения положения наименее обеспеченных членов общества.

Выделение только данных видов справедливости из большого перечня позволяет определить функции социальной справедливости в системе экономических отношений.

Попытки установления связи принципов эффективности и справедливости предпринимались со времен А. Смита, но до сих пор она не установлена.

В бесклассовом обществе единственной формой справедливости признавалась уравниловка. С появлением частной собственности справедливыми стали признавать различия в положении людей, принимая во внимание их достоинства. В классовом обществе стала применяться распределяющая справедливость. Она регулирует распределение и перераспределение благ между членами сообщества. Больше других может получать более достойный член общества. Он имеет право получать долю, соответствующую и его достоинству, и его вкладу и его заслугам. Суммарный критерий распределения может при этом включать как особые качества человека и его достижения в труде, так и принадлежность к какой-то социальной группе, при этом, что особенно важно иметь в виду, величину вклада в уставный капитал предприятия и другие показатели.

В последующем к критериям справедливости стали включать и некоторые показатели результативности хозяйствования. Делались попытки рассмотрения справедливости с точки зрения производства и с точки зрения потребления.

Однако деятельную справедливость с точки зрения экономической свободы авторы пытались охарактеризовать внешними зримыми показателями: уважение человеческого достоинства работников предприятия и потребителей продукции этого предприятия; отсутствие вреда их здоровью, экологии окружающей среды, социальной инфраструктуре окружающей предприятие местности, на вдаваясь в сущностные показатели.

Характеристика потребительской справедливости так же характеризовались поверхностными показателями: меры и культуры выбора и потреблении благ и ресурсов, сдерживания расточительности и социальной напряженности изза усиления поляризации уровня жизни разных социальных групп.

Применяемые формы справедливости в горизонтальном плане характеризуют этическое качество хозяйствования в целом. А формы справедливости в вертикальном срезе характеризуют соответствующий аспект этичности отношений любого уровня управления: от глобального уровня до уровня отдельного предприятия и отдельного сотрудника предприятия.

Применяемые показатели страдают поверхностностью, не отражающей сущности проблема в целом.

В современной экономической теории трактовка справедливости дополнительно включает институциональную составляющую общей характеристики справедливости. В институциональной трактовке справедливости, она представлена как особый институт в общественной структуре, ответственной за экономическое развития.

Исторически пониманию справедливости уделялось древними философами еще до новой эры (Аристотель 384-322 гг. до н.э.). Фома Аквинский (1225-1274) как и Аристотель уделял внимание на два аспекта справедливости - при обмене и при распределении (оставив без внимания производство и потребление). При обмене справедливость характеризуется количественными показателями отношений обмена между частным продавцом и покупателем товаров и других экономических благ. При распределении справедливость характеризуется количественными отношениями при распределении, отношениями целого и частей, отношениями между его частями. «Если обменное право опирается на принцип простого арифметического равенства, то распределительное основано на пропорциональном равенстве. При распределении доходов пропорции, в соответствии с которыми устанавливаются доли дохода, соотносятся с социальным положением гражданина. Справедливость 
распределительного права заключается в том, что каждому воздается по заслугам» [9. С. 159].

Проблема экономической справедливости обострилась при дальнейшем развитии общества, а точнее, когда в обществе появились социальные группы с неравными доходами - богатые и бедные. Существенная неравномерность в распределении доходов сохраняется и сегодня.

Современная (рыночная) система распределительных отношений сталкивается с двумя проблемами:

1) распределением полученного дохода среди собственников факторов производства.

2) распределение дохода между факторами производства.

При абстрагировании от источника получения дохода персональное распределение доходов обеспечивает значительное неравенство между индивидами.

Анализ показывает, что в условиях совершенной конкуренции допускается возможность эффективного распределения экономических ресурсов и благ. Но эффективное распределение даже в этих условиях не обеспечивает справедливости.

Известны несколько подходов к оценке сочетания экономической эффективности и экономической справедливости.

1. В условиях совершенной конкуренции рыночный способ распределения соответствует эффективности использования факторов производства. Неравномерность распределения обусловливается здесь неодинаковым вкладом в достижение эффективности в конечный результат. Экономический рационализм любое распределение признает справедливым. Рыночные монополии усиливают неравномерность распределения. Частное право на собственность обусловливает изначально неравные условия участия работников в производстве благ (возраст, физические и интеллектуальные возможности, обладание собственностью) и обусловливает экономическую несправедливость. В итоге рыночное распределение доходов воспроизводит социально-экономическое неравенство в обществе.

2. Уравнительное распределение благ между людьми считается многими справедливым. Но такое распределение противоречит экономическому росту.

3. Утилитарное распределение товаров и услуг предполагает максимизацию общей по- лезности для всего общества Больший доход должен получать тот, кто приносит большую полезность для общества. Такое распределение стимулирует экономическую эффективность, но не обеспечивает социальную справедливость.

4. Теоретик социального либерализма Дж. Роулз связывал справедливость распределения с максимизацией полезности для наименее обеспеченных членов общества. Общественное благосостояние возрастает по мере увеличения благосостояния наименее обеспеченных членов общества. Неравенство в распределении доходов оправдывается тем, что оно способствует росту низкооплачиваемых групп населения.

\section{3. Экономическая справедливость}

Итак, мы увидели, что во всех рассмотренных теоретических и практических позициях при оценках учитываются показатели экономической и социальной справедливости.

«Если говорить о людях, то в первую очередь, что их интересует, это справедливость, в том числе справедливость в ценах, которые они видят на электроэнергию, на газ, на воду, на соответствующие тарифы. Это также вопросы цен, связанные с жизненно важными лекарствами, то, что всех интересует. И конечно, цены на продукты питания, на все продукты, которыми так или иначе человек пользуется», (Премьер-министр РФ Мишустин М. В., 11.112020$).$

Неравномерность определяется и характеризуется несколькими показателями.

Оценить экономическую справедливость можно следующими показателями: кривой Лоренца, коэффициентом Джини и децильным коэффициентом

Кривая Лоренца показывает долю дохода, которые получают различные группы населения. Эти группы формируются по размеру дохода, получаемого доходов.

На графике ось абсцисс показывают долю населения, а ос ординат - доля доходов в обществе в процентном отношении. Здесь неравенство в распределении доходов, что отражает кривая OABCDE - это и есть кривая Лоренца. Из графика видно, что первые 20\% населения получают 5\% доходов, 40\% населения - 15\% доходов, $60 \%$ населения - 35\% доходов, 80\% населения $60 \%$ доходов, ну и естественно 100\% населения 100\% доходов. Если кривая Лоренца принимает вид прямой линии, то на характеризует абсолютное равенство. 


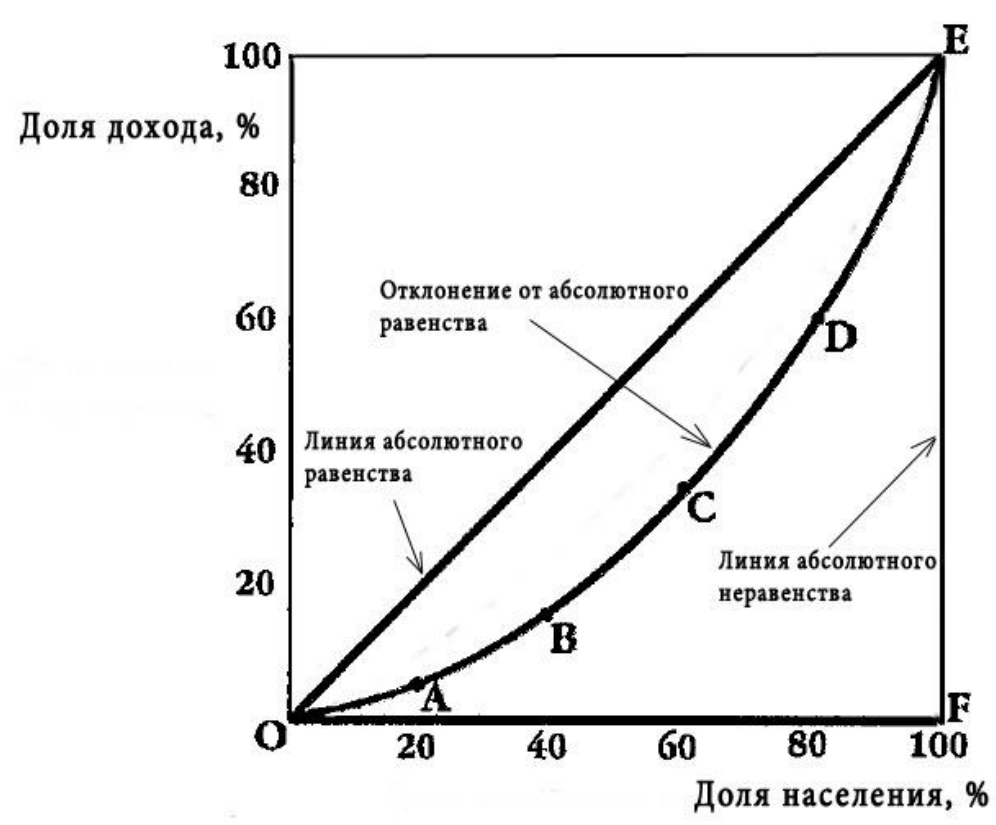

Рuc. 1. Кривая Лоренца.

Степень отклонения линии фактического распределения характеризует коэффициент Джини или коэффициент концентрации доходов. Характеристику этого статистического показателя можно получить по степени отклонения линии фактического распределения на Кривой Лоренца от линии абсолютного равенства. Если доходы распределяются абсолютно равномерно, то низшая 20\%-ная группа населения (нижний квинтиль) получает ровно $20 \%$ совокупного дохода, $60 \%$ населения получает $60 \%$ дохода, а высшая (тоже 20\%-ная группа) ровно такую же долю совокупного дохода $-20 \%$. В реальной же действительности соотношении долей иное. Например, на долю нижнего квинтиля приходилось в США в конце XX в. только $4,2 \%$ совокупного дохода, второго - $10 \%$ и так далее. Группа же богатых, состоящая из 5\% населения, присваивала $20,1 \%$ национального дохода, т.е. больше, чем 40\% всех семей, относящихся к нижним группам.

В России Индекс Джини с 1992 года до 2017 изменился с показателя 0,289 до показателя 0,410 (16).

Более обоснованно экономическая справедливость, по нашему мнению, характеризует показатель децильного коэффициента. Децильный коэффициент можно рассчитать без построения графика. Он рассчитывается путем сопоставления средних доходов $10 \%$ самых богатых жителей государства к такому же проценту беднейших. Меньший показатель децильного коэффициента характеризует стабильную ситуация в обществе. Значение же коэффициента больше 10 означает гипотетическую возможность возникновения гражданских беспорядков, вплоть до возможности государственного переворота. Это связано с тем, что разница в принадлежащих разным «кастам» активов настолько велика, что сразу бросается в глаза несправедливость (17).

С конца 90-х годов прошлого века децильный коэффициент в нашей стране только растет. В 2019 году он достиг показателя 15,6. О справедливости в этой ситуации можно и не говорить (18).

Теоретически и практически экономическую и социальную справедливость можно анализировать с позиции нормативной или позитивной экономики, с позиции возможных вариантов экономических отношений или с позиции существующих экономических отношений.

Проведенный анализ показал, что основная часть исследований отечественных и мировых экономистов предполагают условия рыночной экономики. И это неудивительно, поскольку и наука и образование усилиями Сороса и Ко находится в этом статическом состоянии. Все исследования имеют однозначное целеполагание - совершенствование рыночных отношений. Но практически никто не сомневается, что рыночная экономика может обеспечить в определенной мере только экономическую, а не со- 
циальную справедливость.

Либералы-рыночники экономическое решение проблемы социальной справедливости базируют на представлении общественного продукта как суммы доходов от всех факторов производства: живого туда, используемого капитала, природных ресурсов и предпринимательских способностей. Так оно и просматривается на поверхности экономических отношений. Но если заглянуть внутрь, как это советовали и делали классики экономической теории, то мы увидим за этими факторами труд и только труд.
Видимо пора рассмотреть проблему обеспечения экономической и социальной справедливости на сущностном уровне, не ограничиваясь рамками либерализма, рамками рынка. На каком-то историческом этапе и теория и практика ограничивалась рамками либерализма, рамками «кажимости». Но неспособность обеспечения экономической и социальной справедливости в условиях, ограниченных рамок либерализма, диктует необходимость перехода на научную основу и рассмотрение проблемы на сущностном уровне.

\section{Библиографический список}

1. Боровой А. Общественные идеалы современного человечества. Либерализм. Социализм. Анархизм. Архивная копия от 31 октября 2009 на WaybackMachine М.: Логос, 1906.

2. Вальрас Л. Элементы чистой политической экономии, или Теория общественного богатства. М.: Изограф, 2000.

3. Валлерстайн И. Смерть неолиберальной глобализации. 2008.

4. Вюнше X. Ф. Социальный аспект социального рыночного хозяйства / Социальное рыночное хозяйство как политика введения рыночного хозяйства М., 2016.

5. Глазьев С. Политика социальной справедливости и экономического роста. // Российский экономический журнал.-2012. - № 11/12.

6. Гуськова М.Ф., Стерликов П. Ф., Стерликов Ф.Ф. Экономическая жизнь людей Экономические науки, 2017 № 2 .

7. Гуськова М.Ф., Стерликов П. Ф., Стерликов Ф. Ф. На пути поиска научных принципов экономической периодизации человеческого общества. Экономические науки, 2020, № 4.

8. Зарицкий Б. Е. Немецкий автопром в эпоху глобализации. Мир новой экономики, 2016, № 2. С. 88-94.

9. Жигало Е. А. Модели перераспределения доходов в контексте социальной справедливости 2013

10. Калмычкова Е.Н., Чаплыгина И.Г. Экономическое мышление: Философские предпосылки. ИНФРА-М, 2005. C. 159.

11. Милль Дж. С. Основы политической экономии. М., 1980. Т. 1.

12. Новосадов С. А. Социально-экономическая трансформация глобального развития общества при переходе к новому концептуальному состоянию: предпосылки, тенденции, прогностика: монография.- М.: Креативная экономика, 2016.

13. Петросян Д. О социальной справедливости в экономических отношениях. // Общество и экономика.2010. - № 9.

14. Петросян Д. Гуманистическая экономика и социальная справедливость. // Общественные науки и современность. - 2011.- № 5 .

15. Реализация экономических интересов России при взаимодействии со странами Азии и Ближнего Востока в условиях новых вызовов и возможностей сотрудничества / Абрамов В.Л., Логинов Е.Л., Шкута А.А.Зарицкий Б.Е., Котляров Н.Н., Красавина Л.Н., Поспелов В.К., Ревенко Н.С., Сильвестров С.Н. и др.- М.: Финуниверситет при Правительстве РФ, 2018. - 327 с.

16. Справедливость распределения в рыночной экономике. Концепции справедливости [Электронный ресурс].-- режим достугuпа: https://studwood.ru/1301181/ekonomika/spravedlivost_raspredeleniya_rynochnoy_ ekonomike_kontseptsii_spravedlivosti (дата обращения 24.05.2018).

17. Хайек Ф. А. Дорога к рабству.-М.: «Новое издательство», 2005.-264 с. - ISBN 5-98379-037-4.

18. UROV_32g.doc

19. BusinesVan.ru: https:\\businesanru \new-chtotaroe-decilnyj-koefficient.html

20. as.gov.ru >rusfeb 2020.pdf 